\title{
The Relationship of the Fetal Crown-Rump Length to the Yolk Sac Diameter in Normal Pregnancy
}

\author{
Daniel Faustin*, Cheyenne Cortez, Derek Liang, Katie Soe, Hadiatou Barr and Jennifer Chan \\ Department of Obstetrics Gynecology and Women's Health, Wyckoff Heights Medical Center, USA
}

*Corresponding author: Daniel Faustin, MD, Department of Obstetrics Gynecology and Women's Health, Wyckoff Heights Medical Center, Brooklyn, New York, USA.

Submission: 眥July 09, 2018; Published: 眥 August 15, 2018

\begin{abstract}
Objective: Establish normal values for the ratio of the fetal Crown-Rump Length (CRL) to the yolk sac (YS) diameter during the first trimester of pregnancy and determine whether it correlates with gestational age.

Methods: A retrospective analysis of 1453 pregnancies was undertaken from May 12012 to June 302016 to determine the CRL/YS ratio on uncomplicated pregnancies referred for routine sonographic evaluation between 5 and 11 weeks of gestation at our Maternal Fetal Medicine Unit. Complicated pregnancies, abnormal intrapartum courses and poor fetal birth outcomes were excluded. The mean CRL/YS ratio was established for each gestational age interval and a Pearson coefficient of correlation ( $\mathrm{r}$ ) was calculated with $\mathrm{p}<0.05$ considered significant.
\end{abstract}

Results: The CRL, YS diameter and CRL/YS ratio, all significantly correlate with gestational age. The CRL measurements also correlate with the yolk sac diameters for their corresponding gestational ages $(r=0.995, \mathrm{p}<0.00001)$.

Conclusion: This study provides a reference for the relationship between the CRL, the yolk sac diameter and the CRL/YS ratio with gestational age during the first trimester of normal pregnancy. Given the vital importance of the yolk sac to the health of the first trimester fetus, significant changes in the CRL/YS ratio may predict potential complications of pregnancy beyond the first trimester.

\section{Introduction}

A wanted pregnancy is typically viewed as a time filled with excitement, but the uncertainty about its outcome can be quite worrisome to the patient. Parental concern often begins from the first trimester. Currently, significant data exist regarding normal and abnormal ultrasonographic measurements of the gestational sac (GS), yolk sac (YS), crown-rump length (CRL) in early gestations $[1,2]$. These parameters have been studied for the dual purpose of establishing standardized parameters for each gestational age and predicting early pregnancy failure [3-5]. The yolk sac is the primary source of nutrition, metabolic, immunologic, excretory, and hematopoietic functions prior to placental development, and the CRL is known to accurately correlate with gestational age during the first trimester of pregnancy [6-10]. While these measurements have typically been looked at individually, the current understanding of the relationships between them is limited. The primary purpose of this study is to establish normal values for the ratio of the fetal Crown-Rump Length (CRL) to the yolk sac (YS) diameter during the first trimester of normal pregnancy and determine whether it correlates with gestational age.

\section{Materials and Methods}

This study was conducted at Wyckoff Heights Medical Center in Brooklyn, New York, after obtaining approval from the Institutional
Review Board. A retrospective review of 1453 patient charts from May 1, 2012 to June 30, 2016 was completed. The records were selected chronologically from a list of routine first trimester sonograms performed in the Maternal Fetal Medicine Unit during this time period. After review, a total of 637 records were found to have complete data available, including pregnancy outcomes, for completion of this study. After exclusion of those pregnancies complicated by vaginal bleeding, hypertension, diabetes, severe anemia, fetal growth restriction, fetal macrosomia, preterm labor and delivery, intrapartum cesarean delivery for non-reassuring fetal heart rate tracing, low Apgar scores $(<6)$, fetal anatomic malformation or aneuploidies, missed abortions, threatened abortions, elective pregnancy terminations, multiple gestations, 341 pregnancies with normal pregnancy outcomes were deemed eligible. Data for the normal pregnancy outcomes were stratified by gestational age to establish average values for the YS diameter, the $\mathrm{CRL}$, and the ratio of the CRL to the YS diameter at each gestational week 5 through 11 . The mean CRL/YS ratio was established for each gestational age interval and a Pearson coefficient of correlation (r) was calculated, with $\mathrm{p}<0.05$ considered significant.

\section{Results}

The patients were distributed based on their gestational age intervals: N1 for 5-5 6/7 weeks, N2 for 6- 6 6/7 weeks, N3 for 
7-7 6/7 weeks, N4 for 8-8 6/7 weeks, N5 for 9-9 6/7 weeks, N6

measurements, the yolk sac diameters and the ratio of CRL/YS for 10-10 6/7 weeks and N7 for 11-11 6/7 weeks. The fetal CRL significantly correlate with gestational age (Table 1); (Figure 1-3).

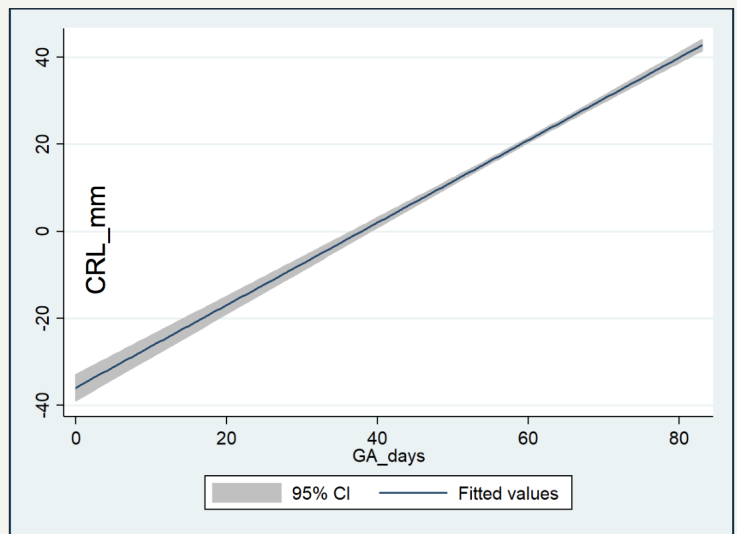

Figure 1: Crown-rump length vs. gestational age.

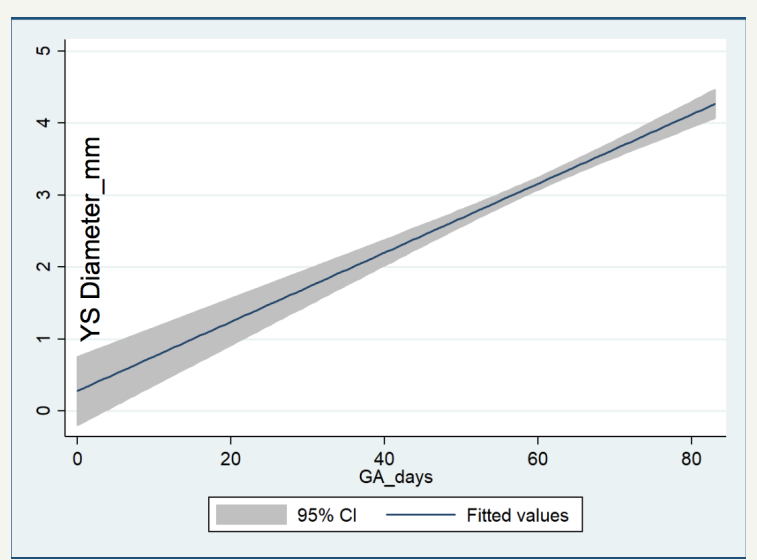

Figure 2: Yolk sac diameter vs. gestational age.

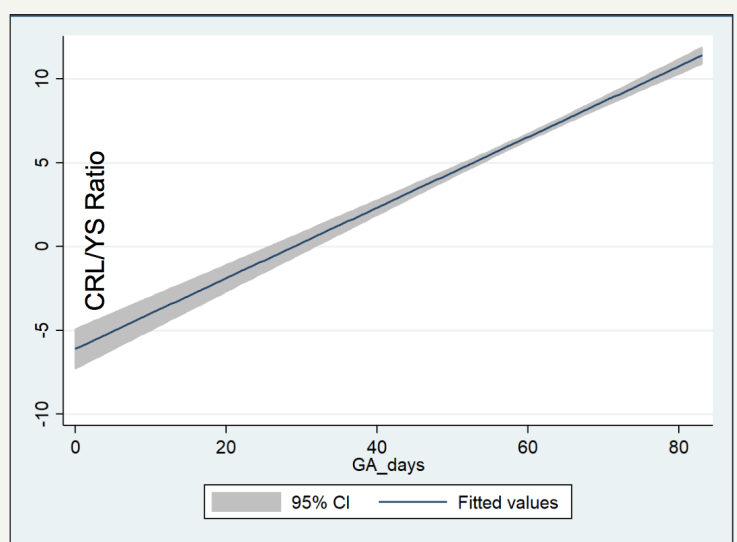

Figure 3: Crown-rump length/yolk sac diameter ratio vs. gestational age.

\section{Discussion}

Our sonographic values for CRL and yolk sac diameters are consistent with accepted standards for the stated gestational ages [3-5]. Our sample comes from a diverse multi-ethnic population with standard measurements potentially applicable to a large variety of communities. Establishing the normal relationship between the fetal crown-rump length and the yolk sac diameter aims at providing an additional tool to those caring for pregnant women, so they may offer valuable information to them about their pregnancies. This study may serve as a precursor to additional research involving complicated pregnancies and the determination of whether any complication may be predictable on the basis of abnormal CRL/YS ratios. Should this be established in the future, it would allow for earlier identification of abnormal pregnancies and the potential for early interventions aimed at improving pregnancy outcomes. 
Table 1: The evolution of CRL measurement, the Yolk Sac Diameter and the CRL/YS ratio as gestational age increases.

\begin{tabular}{|c|c|c|c|c|c|c|c|c|}
\hline Gestational Age Interval & N1 & N2 & N3 & N4 & N5 & N6 & N7 & Correlation \\
\hline CRL (mm) & 2.95 & 6.84 & 11.96 & 19.65 & 26.26 & 35.41 & 41.44 & (r=0.994, p<0.00001 significant) \\
\hline YS(mm) & 2.17 & 2.36 & 2.73 & 2.96 & 3.61 & 3.9 & 4.41 & (r $=0.990, p<0.00001$ significant) \\
\hline CRL/YS & 1.4 & 2.9 & 4.4 & 6.6 & 7.3 & 9.1 & 9.4 & (r $=0.9886, p<0.000026$ significant) \\
\hline
\end{tabular}

\section{Acknowledgement}

We wish to thank Dr. Carolyn Salafia for her assistance with data analysis and for lending her wealth of experience in the field of research.

\section{References}

1. Abdallah Y, Daemen A, Kirk E, Pexsters A, Naji O, et al. (2011) Limitations of current definitions of miscarriage using mean gestational sac diameter and crown-rump length measurements: a multicenter observational study. Ultrasound Obstet Gynecol 38(5): 487-502.

2. Metin AM, Yaz H, Haberal A (2009) The assessment of the gestational sac diameter, crown-rump length, progesterone and fetal heart rate measurements at the $10^{\text {th }}$ gestational week to predict the spontaneous abortion risk. J Obstet Gynaecol Res 35(2): 287-292.

3. Papaioannou GI, Syngelaki A, Maiz N, Ross JA, Nicolaides KH (2011) Ultrasonographic prediction of early miscarriage. Hum Reprod 26(7): 1685-1692.

4. Rodgers SK, Chang C, De Bardeleben J, Horrow MM (2015) Normal and abnormal US findings in early first-trimester pregnancy: Review of the society of radiologists in ultrasound 2012 consensus panel recommendations. Radiographics 35(7): 2135-2148.
5. Yi Y, Lu G, Ouyang Y, Lin G, Gong F, et al. (2016) A logistic model to predict early pregnancy loss following in vitro fertilization based on 2601 infertility patients. Reproductive Biology and Endocrinology, pp. 1-7.

6. Bagratee JS, Regan L, Khullar V, Connnolly C, Moodley J (2009) Reference intervals of gestational sac, yolk sac and embryo volumes using threedimensional ultrasound. Ultrasound Obstet Gynecol 34(5): 503-509.

7. Batmaz G, Aksoy A, Aydin S, Ozcan P, Dane C, et al. (2015) The early pregnancy volume measurements in predicting pregnancy outcome. Clin Exp Obstet Gynecol 43(2): 241-244.

8. Butt K, Lim K (2014) Determination of gestational age by ultrasound. J Obstetrics Gynaecology Canada 36(2): 171-181.

9. Jurkovic D, Gruboeck K, Campbell S (1995) Ultrasound features of normal early pregnancy development. Curr Opin Obstet Gynecol 7(6): 493-504.

10. Pexsters A, Luts J, Van Schoubroeck D, Bottomley C, Van Calster B, et al. (2011) Clinical implications of transvaginal sonographic measurement of gestational sac and crown-rump length at 6-9 weeks' gestation. Ultrasound Obstet Gynecol 38(5): 510-515.
Creative Commons Attribution 4.0

International License

For possible submissions Click Here

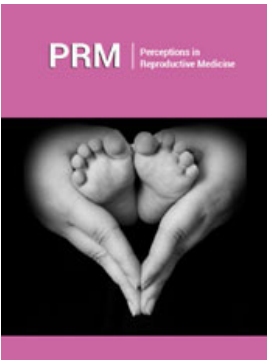

\section{Perceptions in Reproductive Medicine}

\section{Benefits of Publishing with us}

- High-level peer review and editorial services

- Freely accessible online immediately upon publication

- Authors retain the copyright to their work

- Licensing it under a Creative Commons license

- Visibility through different online platforms 